\title{
Effect of Health Belief Model-Based Educational Intervention About Breast Cancer on Nursing Students' Knowledge, Health Beliefs and Breast Self-Examination Practice
}

\author{
Manal Hamed Mahmoud ${ }^{1}$, Samiha Hamdi Sayed ${ }^{2}$, Heba Abdel-Fatah Ibrahim ${ }^{3}$ \& Eman Mohammed \\ Abd-Elhakam ${ }^{3}$ \\ ${ }^{1}$ Medical-Surgical Nursing, Faculty of Nursing, Benha University, Egypt \\ ${ }^{2}$ Community Health Nursing, Faculty of Nursing, Damanhour University, Egypt \\ ${ }^{3}$ Obstetrics and Woman's Health Nursing, Faculty of Nursing, Benha University, Egypt \\ Correspondence: Heba Abdel-Fatah Ibrahim, Obstetrics and Woman's Health Nursing, Faculty of Nursing, \\ Benha University, Egypt.
}

Received: October 14, 2018

Accepted: October 30, 2018

Online Published: November 8, 2018

doi:10.20849/ijsn.v3i3.503

URL: https://doi.org/10.20849/ijsn.v3i3.503

\begin{abstract}
Background: Breast cancer is a global health emergency and it is the principal reason of cancer related deaths in Developing Countries owing to the prevailing cultural beliefs and lack of awareness among women. This study aimed to evaluate the effect of health belief model-based education about breast cancer on nursing students' knowledge, health beliefs and breast self-examination practice.

Subjects and Methods: A quasi-experimental design was utilized. Setting: The study was conducted at the Faculty of Nursing, Benha University, Benha city. A purposive sample of 104 nursing students were included in the study and divided into a study group (52) and control group (52). Three tools were used for data collection; first tool: self-administrated questionnaire to collect data about the subjects' socio-demographic characteristics, and knowledge regarding breast cancer. Second tool: the health belief model scale. Third tool: an observation checklist to assess the nursing students' practice of breast self-examination.

Results: A statistically significant differences were observed between the study and control groups regarding knowledge about breast cancer after educational intervention based on health belief model (t test $=19.53$, $\mathrm{P}=0.000$ ). The mean scores of perceived susceptibility, severity, benefits, cues for action, self-efficacy and total heath belief model were significantly higher in the study group compared to control group $(P=0.000)$. Moreover a statistically significant difference was observed between both groups regarding breast self-examination practice after educational intervention ( $\mathrm{t}$ test $=31.266, \mathrm{P}=0.000$ ).

Conclusion and recommendation: The health belief model based education is an effective and efficient manner in enhancing girls' breast self-examination practice and improving their knowledge level and health beliefs about breast cancer. Thus the current study recommends implementing health belief model based educational intervention about breast cancer at different stages of life and settings to reach all targeted women to fight the disease.
\end{abstract}

Keywords: breast cancer, breast self-examination, health belief model

\section{Introduction}

Cancer is an ever rising public health problem both in developed and developing countries that influences nearly two thirds of the world population (United Nations, World Cancer Day, 2017; Jemal, et al., 2010). World Health Organization (WHO) had announced in the World Cancer Day in 2018 that cancer is currently responsible for almost one in six deaths worldwide. It is also considered to be the second leading cause of death globally causing about 8.8 million deaths in 2015 where about $70 \%$ of all cancer related deaths occurred either in low and middle income countries. Based on the WHO estimates Breast Cancer (BC) is not only one of the most widespread cancers but also it is one of the leading causes of cancer death accounting for 571.000 deaths among females worldwide in 2015 (WHO, 2018). It is considered to be a global health emergency where every 3 minutes a 
woman is diagnosed with $\mathrm{BC}$ with 1.7 million new cases yearly and it is the principal reason of cancer related deaths in developing countries (United Nations, World Cancer Day, 2017).

In Egypt, recently WHO in 2014 had announced that BC is the most common cancer among Egyptian women with the mean age at diagnosis is ten years lower than in the United States and Europe (WHO, 2014). The Egypt National Cancer Registry Program (NCRP) indicated in 2014 that BC occupied the second position after liver cancer which both accounting for about $45 \%$ of all cancers in both sexes. It accounts for $32.0 \%$ of cancer cases among Egyptian females with high dominated frequency in Lower, Middle, and Upper Egypt $(33.8 \%, 26.8 \%$ and $38.7 \%$ respectively) (Ibrahim et al., 2014).

Breast cancer is almost the most horrible cancer owing to its extreme psychological influence on women's identity (Singh \& Jangra, 2013; Obaji, et al., 2013) It is a heterogeneous disease with unknown cause yet it has multidimensional risk factors specifically; genetic predisposition, family history, personal history, female sex and increasing age. In addition to, hormonal related risk factors (estrogen and progesterone) such as late menarche, early menopause, infertility, having first pregnancy after age of 30, hormonal therapy and long term use of contraceptives which increase the risk of $\mathrm{BC}$ through stimulating genotoxic stress and breast tissue mutations. Women's exposure to ionizing radiation even in low doses especially during puberty, unhealthy life styles (e.g., inactivity, poor dietary habits, smoking, and alcohol intake), overweight and obesity play a role too. A recent meta-analytic study found that being a diabetic woman with hyperinulinemia induced tumor genesis effects by binding with breast tissue cells insulin receptors (WHO, 2018; Michael, 2017; Anothaisintawee et al., 2013).

Currently, primary preventive measures of $\mathrm{BC}$ are limited and assuming the significance of early detection in enhancing women quality of life and decreasing associated mortality. Thus screening is the paramount secondary preventive measure for attaining such goals (WHO, 2014; 10. American College of Obstetricians and Gynaecologists, 2011). Notably, WHO in 2018 delineated that around 30-50\% of cancers can be inhibited through avoidance of risk factors and screening measures (WHO, 2018). The suggested screening approaches for early identification of BC are: mammography, clinical breast examination and Breast Self-Examination (BSE). Although mammography screening is the gold standard technique for the early recognition of $\mathrm{BC}$, it is painful, can result in either false positive or high false negative results in thick breast tissues and it is eligible annually for women at age of 45 years (American College of Obstetricians and Gynaecologists, 2011; Oeffinger et al., 2015).

Notably, Breast self-examination (BCE) is a health protective behavior that is recommended for all women as it can be monthly performed at any age starting from 20 years. It is considered to be the easiest, costless and noninvasive screening technique that aid being familiar with the scenery of breasts and observing any signs of changes (swelling, skin irritation or dimpling, nipple retraction, redness, nipple discharge) and feeling of any abnormalities as scaliness or thickening of the nipple or breast skin and masses or lumps in breast and/or axilla (Oeffinger et al., 2015; Shalini et al., 2011\& Harris, 2014 ) BSE is recommended by WHO as an individual measure for raising women awareness about BC risks and its early detection. However, overutilization of BSE and improper performance can lead to misleading or false results. Thus, the American Cancer Society screening guidelines for BC in 2015 further suggested that women should be informed about the possible advantages, disadvantages of BSE and the value of immediate reporting of any discovered breast changes to health professionals (WHO, 2018; Oeffinger et al., 2015).

Despite the great benefits of BSE and BC screening procedures, their utilization remains very low. This unfortunately was found to be due to women's beliefs and lack of awareness which can further influence their screening behavior. Thus, evidence portrayed that behavior-based educational intervention that take into consideration women's beliefs can aid women in overcoming their individual hindrances and encourage them to seek and sustain regular screening behavior. Effective health education mainly depends on adaptation of proper theories/models that are best match to each occasion. One of the models which can be effective in studying preventive cancer behaviors is the Health Belief Model (HBM) (Russell, et al., 2010; Lin \& Effken, 2010 ; Kim et al., 2010 and Oyekale, 2010).

HBM is a psychosocial model for behavior change through examining health behaviors to recognize associated factors with individuals' beliefs which further can affect their decision making process for engaging in preventive health behaviors. Over the years HBM was modified to include six constructs which centered around the chief assumption of the model which depends on the notion that altering the health beliefs is the principal for behavior change (WHO, 2012).

HBM postulates that individuals' participation in certain actions for prevention, early detection, and management of a particular health condition is conditioned by their perception and believe that they are susceptible to such 
condition even if they are asymptomatic (perceived susceptibility); understand that the disease is grave public health problem which can lead to serious complications (perceived severity); believe in the benefits of the recommended preventive actions (perceived benefits); and also understand that these benefits outweigh the expected barriers associated with such actions (perceived barriers). Thereafter, they believe that they possess the motive for living a healthy lifestyle and the required ability to perform these preventive behaviours (self-efficacy). Moreover, the model supposed that cues to action can act as behavior stimuli which may be divided to internal (e.g., previous history for the disease) or external (e.g., mass media, health team) which further increased the likelihood of engaging in such preventive health behaviours (Ghanbary, et al., 2015; Chanay \& Anderson, 2016).

\subsection{Significance of the Study}

$\mathrm{BC}$ is thought to be a public health emergency thus its confronting is a necessity through the preventable nature of the disease. Consequently, Healthy People 2020 put a chief goal delineated to decrease the new cancer cases along with cancer associated illness, disability and death. This goal can't be achieved with the wave of lack of awareness about $\mathrm{BC}$ among women where several evidences showed that women mainly present with end stages $\mathrm{BC}$ owing to dearth of information, knowledge and understanding of early detection measures (Arevian et al., 2011; Othman, et al., 2015). Evidently, Egypt Demographic Health Survey (EDHS) in 2015 revealed that only $11 \%$ of women aged 15-59 years were aware of how to conduct BSE to recognize signs of BC and only $6 \%$ of them were actually had performed BSE in the previous year (Ministry of Health and Population, 2015). Therefore, the current study was conducted with the aim of evaluating the effect of health belief model-based educational intervention about BC on nursing students' knowledge, health beliefs and practices of BSE. Furthermore, it focused on nursing students as they are the future health care providers and knowledge disseminator beside increasing their aware of their own believes which can further reputed myths about BC among population.

\subsection{Aim of the Study}

This study aimed to evaluate the effect of health belief model-based educational intervention on nursing students' knowledge, health and BSE practice through the following objectives:

- Assessing the nursing students' knowledge, health beliefs regarding BC and breast self-examination practice.

- Designing and implementing an educational intervention based on HBM according to students' needs.

- Evaluating the effect of the educational intervention on nursing student's knowledge, health beliefs regarding $\mathrm{BC}$ and breast self-examination practice.

\subsection{Research Hypothesis}

Nursing students who receive the educational intervention about BC based on HBM exhibit higher knowledge level and positive health beliefs about BC and BSE along with higher BSE practice score than the control group.

\section{Materials and Method}

\subsection{Research Design}

A quasi-experimental design (pre-post-test control group) was utilized to accomplish the aim of this study.

\subsection{Setting}

The current study was conducted at the Faculty of Nursing, Benha University, Benha city.

\subsection{Sampling}

A purposive sample of 104 nursing students representing 30\% of the total number of the female nursing students (345) who enrolled in first and second year at Faculty of nursing, Benha University. The sample was randomly divided into an intervention (52) and control (52) group. The reasons of selecting the first and second academic years are because they had no previous education about BC or BSE. Besides, the cultivation of BSE practice at earlier stage of life can have an enduring effect on young girls' performance of BSE as a healthy habit throughout life.

\subsection{Tools of Data Collection}

Three tools were used for collecting the data:

Tool I: Self administrated questionnaire: It included the following parts;

- Part (1): Socio-demographic data; academic year, age, residence, marital status and educational level of the mother and family history of breast cancer. 
- Part (2): knowledge assessment sheet: it was developed by the researchers in Arabic language based on thorough review of relevant literature (Ignatavicius \&Workman, 2016; Bacon \& Tomich, 2017). This part was used before and after implementation of the HBM (pre/ post-test format). It included 19 questions either open (8) and closed (11) ended questions to assess nursing students' knowledge regarding breast cancer; definition, signs and symptoms, risk factors, and early management measures. In addition to, $\mathrm{BC}$ screening measures including breast-self-examination (starting age, number of times, and proper timing of its performance).

The knowledge score for open ended questions (8) was scored on three point scale; (2) correct and complete answer, (1) correct but incomplete answer, and (0) for incorrect or unknown answer with total scores ranged from 0-16. Closed ended questions (11) were also scored as follows; (1) correct answer and (0) for incorrect or unknown answer with total scores ranged from $0-11$. The correct answers were pre-determined according to the literature. The total knowledge score ranged from 0 to 27 where the higher score reflect higher level of knowledge.

\section{Tool II: Health belief model scale:}

It was adapted from the refined version of the Champion Heath Belief Model Scale for breast cancer (Champion, 1993). Modifications were done by the researchers in Arabic language. It was used to assess the students' health beliefs about breast cancer. The scale composed of 22 items rated on 5-point Likert scale ranged from 1 (strongly disagree) to 5 (strongly agree) and distributed over 6 constructs as follows: perceived susceptibility (4) with total score ranged between 4- 20; perceived severity (4), with total score ranged between 4- 20; perceived barriers (5) with total score ranged between 5-25; perceived benefits (3) with total score ranged between 3-15; cues for action (2) with total score ranged between 2-10; and self-efficacy (4) with total score ranged between 4-20. The total HBM score was calculated by summing up the score of each construct which created a total score ranged from 22 to 110. The higher score indicated more positive beliefs toward $\mathrm{BC}$ and its preventive and screening behaviors.

\section{Tool III: An observation checklist:}

It was used to assess nursing students' skills in performing BSE. It was prepared by the investigators based on the previous literatures (Yarbro et al., 2011; Bacon \& Tomich, 2017). It composed of 18 items describing the steps of performing BSE. The observational score was rated on three point scale for each step; (2) correctly done, (1) incorrectly done and (0) if not done; this further created a total score ranged between 0-36.

\subsubsection{Content Validity}

All tools of the current study were reviewed by 5 experts in the field to ensure its clarity and applicability. The tools were modified according to the experts' judgment on simplicity of the sentences and appropriateness of the content.

\subsubsection{Reliability}

Reliability of the tools was tested by using Cronbach's Alpha coefficient test. The scores revealed that each of the three tools consisted of relatively homogenous items as indicated by the moderate to high reliability. An internal consistency of tool $\mathrm{I}=0.72$, tool $\mathrm{II}=0.81$, and tool $\mathrm{III}=0.78$.

\subsection{Ethical Considerations}

An ethical agreement was obtained from the Dean of Faculty of Nursing at Benha University to conduct this study after explaining its aim. In addition, informed oral consent was obtained from the participants of the study and they were informed that their participation in the study was elective and they have the right to withdraw from the study at any time. Participants secured that their responses would be secret and only cumulative data would be communicated. After the study was completed, handout about BC was distributed to the control group.

\subsection{Pilot Study}

A pilot study was accomplished on ten percent of the nursing students (10 students) to test the suitability and implication of the study tools and to test simplicity of the designed questionnaire and HBM scale as well as to estimate the time required for answering. Those subjects in the pilot study were excluded from the study sample since some modifications were done.

\subsection{Field Work}

A written official agreement was obtained from the Dean of the Faculty of Nursing at Benha University to conduct the study after explaining its purpose. The study was carried out through four phases: assessment, 
planning, implementation, and evaluation. These phases were carried out over a period of five months from the beginning of October 2017 to the end of February 2018.

- Assessment phase: Upon securing official approval to conduct the study, the researchers interviewed the students in both control and intervention groups to explain the aim and procedures of the study and ask for their participation. Upon consent to participate, the students were interviewed to assess their demographic characteristics and knowledge regarding BC, HBM, and preventive practices of BC. The data was obtained during this phase constituted the baseline for further comparisons to assess the effect of the program. To avoid cross contamination of data between both groups, control group was assessed first.

- Planning and implementation phase: Based on the needs identified in the assessment phase from the intervention group and in view of the related literature, the researchers developed power point presentation about BC based on HBM with simple Arabic language to suit students' level of understanding. It stressed the areas of major deficiency in students' knowledge about BC which included definition, incidence, risk factors, signs and symptoms, management measures, screening measures for early detection of breast cancer, and technique of BSE. The educational intervention involved three sessions that were conducted on small group (10-12) of the intervention group. The educational intervention was implemented according to students' physical and mental readiness. The duration of each session lasted from twenty to thirty minutes including periods of discussion according to their achievement, progress and feedback. Different methods of teaching were used such as lecture, group discussion, brainstorming and demonstration.

- Evaluation phase: After education based on HBM; the effect of the educational intervention was evaluated by using the same format of pre-test after two months of program implementation using post-test which was conducted for the control group first then the intervention group.

\subsection{Statistical Analysis}

The Statistical Package for Social Sciences (SPSS version 20.0) was used to perform statistical analysis. Descriptive statistics were applied (e.g., mean, standard deviation, frequency and percentages). Significance tests (Chi-square, Monte Carlo test, independent t test and paired t test) were used to test the significant differences between the groups. Pearson correlation coefficients were used to determine the correlation between students' knowledge, health beliefs and BSE practice. The cut off value for statistically significant difference was considered at $\mathrm{p}$-value $\mathrm{p} \leq 0.05$.

\section{Results}

Table 1 illustrates no statistically significant difference between the study and control groups in relation to their socio-demographic characteristics. The highest percent $(51.9 \%, 53.8 \%)$ of both the study and control groups were enrolled in the first academic year with a nearly equal mean age of both groups 19.35 \pm 1.42 and 19.77 \pm 1.47 , respectively. Urban residency was prevalent in both study (88.4\%) and control group (84.6\%). Additionally, $34.6 \%$ of the study group's mothers had secondary education however $32.7 \%$ of the control group's mothers were only read and write. The majority $(88.5 \%, 82.7 \%)$ of both the study group and control group were unmarried, respectively.

Figure 1 declares that a minority $(7.7 \%, 11.5 \%)$ of both the study and control groups have a family history of BC, respectively with no statistically significant difference between both groups (X $2=0.178 \mathrm{p}$ value 0.642 ).

Table 2 shows no statistically significant difference between the study and control group in relation to their BSE performance. The highest percent of both study and control groups $(69.2 \%, 73.1 \%)$ didn't perform BSE, respectively. The frequency of BSE among those who perform BSE was once per month among $50.0 \%$ of the study group and $60.0 \%$ of the control group.

Table 3 portrays no statistically significant difference between both the study and control groups mean total knowledge score before educational intervention ( $\mathrm{t}$ test $=0.24, \mathrm{P}=0.809$ ). On the other hand, after educational intervention a statistically significant difference was observed between both the study and control groups in the mean total knowledge score $(\mathrm{t}$ test $=19.53, \mathrm{P}=0.000$ ). Furthermore, a statistically significant difference was observed within the study group before and after educational intervention (Paired t test $=29.047, \mathrm{P}=0.000$ ) however the difference within the control group was insignificant (Paired t test =1.098, $\mathrm{P}=0.278$ ).

Table 4 illustrates no statistical significant differences were observed between the study and control groups total and all HBM constructs before educational intervention. However, after the educational intervention a highly statistically significant differences $(\mathrm{P}=0.000)$ were observed between both groups in the total and all HBM constructs; perceived susceptibility, severity, benefits, barriers, self-efficacy, and cues to action. Moreover, a general improvement $(\mathrm{P}=0.000)$ in the total and all HBM constructs mean scores were observed within the 
intervention group two months after educational intervention as compared to before it. However, no statistically significant differences were observed within the control group.

Table 5 shows no statistically significant difference was found between both the study and control groups mean total BSE practice score before educational intervention ( $\mathrm{t}$ test $=0.727, \mathrm{P}=0.469$ ). On the other hand, after educational intervention a statistically significant difference was observed between both groups where the mean score of BSE practice is higher in the study than the control group ( $\mathrm{t}$ test $=31.266, \mathrm{P}=0.000$ ). Furthermore, a statistically significant difference was observed within the study group before and two months after educational intervention (Paired t test $=25.861, \mathrm{P}=0.000$ ) however the difference within the control group is insignificant (Paired t test $=0.645, \mathrm{P}=0.522$ ).

Table 6 indicates a statistically significant correlation between both the study and control groups' total knowledge and health belief scores before educational intervention $(\mathrm{r}=0.474, \mathrm{P}=0.000),(\mathrm{r}=0.362, \mathrm{P}=0.008)$ respectively, and after educational intervention $(\mathrm{r}=0.722, \mathrm{P}=0.000),(\mathrm{r}=0.407, \mathrm{P}=0.003)$, respectively. There is also a statistically significant correlation between both the study and control groups' total knowledge and total BSE practice score before educational intervention $(\mathrm{r}=0.639, \mathrm{P}=0.000),(\mathrm{r}=0.905, \mathrm{P}=0.000)$ and two months after educational intervention $(\mathrm{r}=0.503, \mathrm{P}=0.000),(\mathrm{r}=0.900, \mathrm{P}=0.000)$, respectively.

Table 7 portrays a statistically significant correlation between both the study and control groups' total health belief and BSE scores before educational intervention $(\mathrm{r}=0.626, \mathrm{P}=0.000),(\mathrm{r}=0.434, \mathrm{P}=0.001)$ and two months after educational intervention $(\mathrm{r}=0.719, \mathrm{P}=0.000),(\mathrm{r}=0.472, \mathrm{P}=0.000)$, respectively.

Table 1. Distribution of the study and control groups according to their socio-demographic characteristics $(n=104)$

\begin{tabular}{|c|c|c|c|c|c|c|}
\hline \multirow[t]{2}{*}{ Item } & \multicolumn{2}{|c|}{ Study group $(n=52)$} & \multicolumn{2}{|c|}{ Control group $(n=52)$} & \multirow[t]{2}{*}{ Significance test } & \multirow[t]{2}{*}{ p value } \\
\hline & No & $\%$ & No & $\%$ & & \\
\hline Academic year & & & & & $\mathrm{X}^{2}=0.039$ & 0.844 \\
\hline$-\quad 1^{\mathrm{st}}$ & 27 & 51.9 & 28 & 53.8 & & \\
\hline$-\quad 2^{\text {nd }}$ & 25 & 48.1 & 24 & 46.2 & & \\
\hline Age $($ years) Mean \pm SD & \multicolumn{2}{|c|}{$19.35 \pm 1.42$} & \multicolumn{2}{|c|}{$19.77 \pm 1.47$} & $\mathrm{t}=0.507$ & 0.613 \\
\hline Residence & & & & & $X^{2}=0.330$ & 0.566 \\
\hline - Urban & 46 & 88.4 & 44 & 84.6 & & \\
\hline - $\quad$ Rural & 6 & 11.6 & 8 & 15.4 & & \\
\hline Marital status & & & & & $X^{2}=0.701$ & 0.402 \\
\hline - $\quad$ Married & 6 & 11.5 & 9 & 17.3 & & \\
\hline - Unmarried & 46 & 88.5 & 43 & 82.7 & & \\
\hline Mother level of education & & & & & $X^{2}=0.188$ & 0.980 \\
\hline - University education & 6 & 11.5 & 6 & 11.5 & & \\
\hline - $\quad$ Secondary education & 18 & 34.6 & 16 & 30.8 & & \\
\hline - $\quad$ Read and write & 16 & 30.7 & 17 & 32.7 & & \\
\hline - $\quad$ Illiterate & 12 & 23.07 & 13 & 25.0 & & \\
\hline
\end{tabular}

$\mathrm{X}^{2}$ : chi square test, $\mathrm{t}=$ Independent $\mathrm{t}$ test 


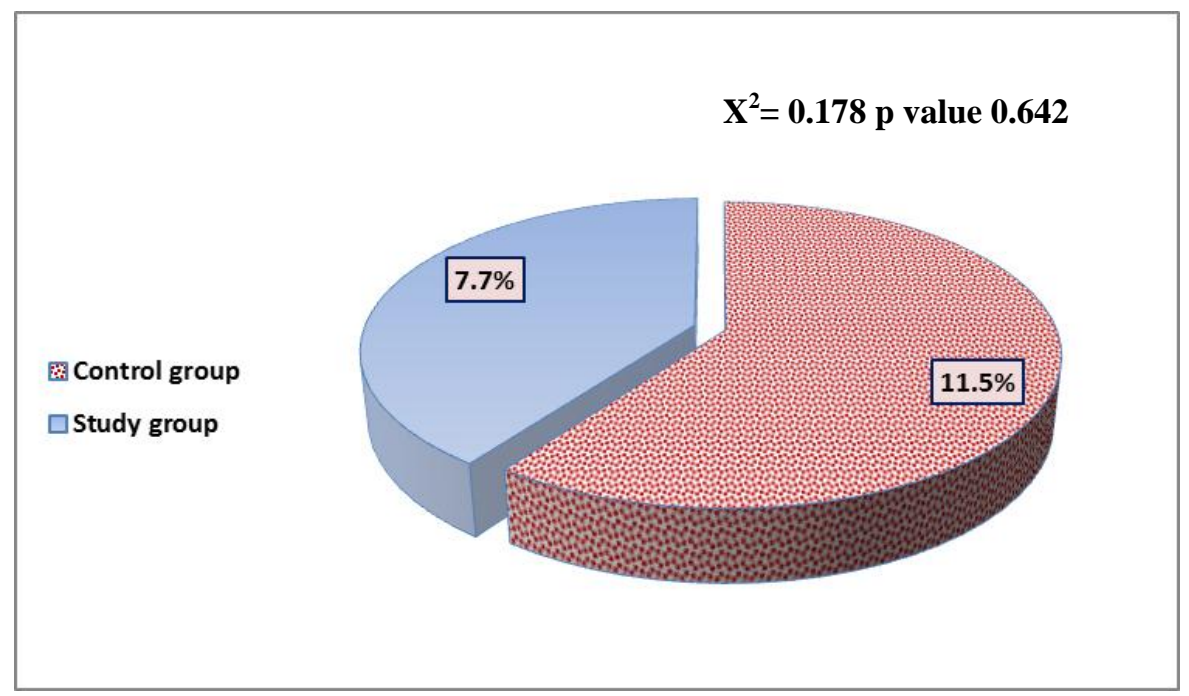

Figure 1. Distribution of the study and control group according to their family history of breast cancer $(n=104)$

Table 2. Distribution of the study and control groups according to their performance of breast self-examination before educational intervention $(n=104)$

\begin{tabular}{|c|c|c|c|c|c|c|}
\hline \multirow[b]{2}{*}{ Items } & \multicolumn{2}{|c|}{ Study group $(n=52)$} & \multicolumn{2}{|c|}{ Control group $(n=52)$} & \multirow{2}{*}{$\begin{array}{c}\text { Significance } \\
\text { test }\end{array}$} & \multirow{2}{*}{$\begin{array}{c}\mathbf{p} \\
\text { value }\end{array}$} \\
\hline & No & $\%$ & No & $\%$ & & \\
\hline Perform breast self-examination & & & & & $\mathrm{X}^{2}=0.187$ & 0.665 \\
\hline - Yes & 16 & 30.8 & 15 & 28.9 & & \\
\hline$-\quad$ No & 36 & 69.2 & 38 & 73.1 & & \\
\hline Frequency of BSE performance & & & & & ${ }^{\mathrm{MC}}=0.170$ & 0.244 \\
\hline - Once a month & 8 & 50.0 & 9 & 60.0 & & \\
\hline - $\quad$ Once every two months & 4 & 25.0 & 0 & 0.0 & & \\
\hline - $\quad$ Once every 6 months & 4 & 25.0 & 6 & 40.0 & & \\
\hline
\end{tabular}

${ }^{\mathrm{MC}}$ : Mont Carlo test, $\mathrm{X}^{2}$ : chi square test

Table 3. Mean differences between the study and control groups' total knowledge score regarding breast cancer before and two months after educational intervention $(n=104)$

\begin{tabular}{|c|c|c|c|c|c|c|}
\hline \multicolumn{7}{|c|}{ Total knowledge score } \\
\hline \multirow{2}{*}{$\begin{array}{c}\text { HBM program } \\
\text { Maximum score }=(27)\end{array}$} & \multirow{2}{*}{\multicolumn{2}{|c|}{$\begin{array}{c}\text { Study group }(n=52) \\
\text { Mean } \pm \text { SD }\end{array}$}} & \multirow{2}{*}{\multicolumn{2}{|c|}{$\begin{array}{c}\text { Control group }(n=52) \\
\text { Mean } \pm \text { SD }\end{array}$}} & \multicolumn{2}{|c|}{ Significance between groups } \\
\hline & & & & & t test & $P$ value \\
\hline - $\quad$ Before intervention & \multicolumn{2}{|c|}{$9.69 \pm 3.52$} & \multicolumn{2}{|c|}{$9.88 \pm 4.50$} & 0.24 & 0.809 \\
\hline $\begin{array}{ll}\text { - } 2 \text { months after } \\
\text { intervention }\end{array}$ & \multicolumn{2}{|c|}{$25.23 \pm 3.46$} & \multicolumn{2}{|c|}{$10.28 \pm 4.29$} & 19.533 & $0.000 *$ \\
\hline \multirow{2}{*}{$\begin{array}{l}\text { Significance within group } \\
\text { (before and after } \\
\text { intervention) }\end{array}$} & $\begin{array}{c}\text { Paired } \\
(\mathbf{t})\end{array}$ & $\begin{array}{c}(\mathbf{P}) \\
\text { Value }\end{array}$ & $\begin{array}{c}\text { Paired } \\
\text { (t) }\end{array}$ & $\begin{array}{c}(\mathbf{P}) \\
\text { Value }\end{array}$ & & \\
\hline & 29.047 & $0.000 *$ & 1.098 & 0.278 & & \\
\hline
\end{tabular}

Independent $t$ test was used to determine the significance between study and control group, paired t test was used to determine the significance within group. *P significant at $\leq 0.05$ 
Table 4. Mean differences between the study and control groups regarding HBM constructs before and two months after educational intervention $(n=104)$

\begin{tabular}{|c|c|c|c|c|c|c|c|c|}
\hline \multirow{3}{*}{$\begin{array}{l}\text { Constructs of Health Belief } \\
\text { Model } \\
\text { (maximum score) }\end{array}$} & \multicolumn{4}{|c|}{ Before intervention } & \multicolumn{4}{|c|}{2 months after intervention } \\
\hline & \multirow{2}{*}{$\begin{array}{c}\text { Study group } \\
(\mathrm{n}=\mathbf{5 2}) \\
\text { Mean } \pm \text { SD }\end{array}$} & \multirow{2}{*}{$\begin{array}{l}\text { Control group } \\
\qquad(\mathbf{n}=\mathbf{5 2}) \\
\text { Mean } \pm \text { SD }\end{array}$} & \multicolumn{2}{|c|}{$\begin{array}{c}\text { Significance } \\
\text { between groups }\end{array}$} & \multirow{2}{*}{$\begin{array}{l}\text { Study group } \\
(\mathrm{n}=\mathbf{5 2}) \\
\text { Mean } \pm \text { SD }\end{array}$} & \multirow{2}{*}{$\begin{array}{l}\text { Control group } \\
\qquad(n=52) \\
\text { Mean } \pm \text { SD }\end{array}$} & \multicolumn{2}{|c|}{$\begin{array}{c}\text { Significance } \\
\text { between groups }\end{array}$} \\
\hline & & & $t$ test & $P$ value & & & t test & $P$ value \\
\hline Perceived susceptibility (20) & $9.35 \pm 2.32$ & $9.71 \pm 2.62$ & 0.752 & 0.454 & $15.4 \pm 1.59$ & $10.35 \pm 2.57$ & 11.178 & $0.000^{*}$ \\
\hline $\begin{array}{l}\text { Significance within group Paired } \\
\mathrm{t} \text { test ( } \mathrm{p} \text { value) }\end{array}$ & \multicolumn{4}{|c|}{$\begin{array}{l}\text {-Study group: } t=20.776\left(p=0.000^{*}\right) \\
\text {-Control group: } t=1.399(p=0.168)\end{array}$} & & & & \\
\hline Perceived severity(20) & $15.00 \pm 1.77$ & $15.5 \pm 1.99$ & 0.426 & 0.678 & $18.62 \pm 1.61$ & $15.85 \pm 2.02$ & 7.633 & $0.000 *$ \\
\hline $\begin{array}{l}\text { Significance within group Paired } \\
\mathrm{t} \text { test ( } \mathrm{p} \text { value) }\end{array}$ & \multicolumn{4}{|c|}{$\begin{array}{l}- \text { Study group: } t=11.366\left(p=0.000^{*}\right) \\
- \text { Control group: } t=1.000(p=0.322)\end{array}$} & & & & \\
\hline Perceived barriers (25) & $16.38 \pm 3.09$ & $16.37 \pm 3.10$ & 0.032 & 0.975 & $14.12 \pm 1.61$ & $17.67 \pm 2.84$ & 8.264 & $0.000 *$ \\
\hline $\begin{array}{l}\text { Significance within group Paired } \\
\mathrm{t} \text { test }(\mathrm{p} \text { value })\end{array}$ & \multicolumn{4}{|c|}{$\begin{array}{l}\text {-Study group: } \mathrm{t}=11.490\left(\mathrm{p}=0.000^{*}\right) \\
\text {-Control group: } \mathrm{t}=1.352(\mathrm{p}=0.182)\end{array}$} & & & & \\
\hline Perceived benefits (15) & $12.15 \pm 1.33$ & $12.25 \pm 1.38$ & 0.361 & 0.719 & $14.42 \pm 0.75$ & $12.58 \pm 1.41$ & 8.294 & $0.000 *$ \\
\hline $\begin{array}{l}\text { Significance within group Paired } \\
\mathrm{t} \text { test }(\mathrm{p} \text { value })\end{array}$ & \multicolumn{4}{|c|}{$\begin{array}{l}\text {-Study group: } t=14.359\left(p=0.000^{*}\right) \\
\text {-Control group: } t=1.000(p=0.322)\end{array}$} & & & & \\
\hline Self-efficacy (20) & $11.53 \pm 1.46$ & $11.46 \pm 1.50$ & 0.266 & 0.791 & $16.82 \pm 123$ & $11.48 \pm 1.44$ & 20.273 & $0.000 *$ \\
\hline $\begin{array}{l}\text { Significance within group Paired } \\
\mathrm{t} \text { test ( } \mathrm{p} \text { value) }\end{array}$ & \multicolumn{4}{|c|}{$\begin{array}{l}\text {-Study group: } t=35.577(p=0.000 *) \\
\text {-Control group: } t=1.137(p=0.261)\end{array}$} & & & & \\
\hline Cues to action/motivation (10) & $4.63 \pm 0.90$ & $4.55 \pm 0.96$ & 0.430 & 0.668 & $8.00 \pm 0.84$ & $4.59 \pm 1.01$ & 18.631 & $0.000^{*}$ \\
\hline $\begin{array}{l}\text { Significance within group Paired } \\
\mathrm{t} \text { test }(\mathrm{p} \text { value })\end{array}$ & \multicolumn{8}{|c|}{$\begin{array}{l}\text {-Study group: } \mathrm{t}=24.390\left(\mathrm{p}=0.000^{*}\right) \\
\text {-Control group: } \mathrm{t}=-0.814(\mathrm{p}=0.420)\end{array}$} \\
\hline Total HBM score (110) & $69.05 \pm 4.74$ & $71.84 \pm 5.92$ & 0.532 & 0.769 & $94.32 \pm 3.17$ & $72.23 \pm 4.57$ & 24.719 & $0.000 *$ \\
\hline $\begin{array}{l}\text { Significance within group Paired } \\
\mathrm{t} \text { test ( } \mathrm{p} \text { value) }\end{array}$ & \multicolumn{4}{|c|}{$\begin{array}{l}\text {-Study group: } t=35.155\left(\mathrm{p}=0.000^{*}\right) \\
\text {-Control group: } \mathrm{t}=1.187(\mathrm{p}=0.345)\end{array}$} & & & & \\
\hline
\end{tabular}

Independent $\mathrm{t}$ test was used to determine the significance between study and control group, paired $\mathrm{t}$ test was used to determine the Significance within group, *P significant at $\leq 0.05$

Table 5. Mean differences between the study and control groups regarding the total BSE practice score before and two months after educational intervention $(n=104)$

\begin{tabular}{|c|c|c|c|c|c|c|}
\hline \multicolumn{7}{|c|}{ Total practice score } \\
\hline \multirow{2}{*}{$\begin{array}{c}\text { HBM program } \\
\text { Maximum score }=(36)\end{array}$} & \multirow{2}{*}{\multicolumn{2}{|c|}{$\begin{array}{c}\text { Study group }(n=52) \\
\text { Mean } \pm S D\end{array}$}} & \multirow{2}{*}{\multicolumn{2}{|c|}{$\begin{array}{c}\text { Control group }(n=52) \\
\text { Mean } \pm \text { SD }\end{array}$}} & \multicolumn{2}{|c|}{ Significance between groups } \\
\hline & & & & & t test & $P$ value \\
\hline - $\quad$ Before intervention & & \pm 4.56 & & $25 \pm 3.76$ & 0.727 & 0.469 \\
\hline $\begin{array}{ll}\text { - } & 2 \text { months after } \\
\text { intervention }\end{array}$ & & \pm 1.48 & & $17 \pm 3.70$ & 31.266 & $0.000^{*}$ \\
\hline $\begin{array}{l}\text { Significance within group } \\
\text { (before and after } \\
\text { educational intervention) }\end{array}$ & $\begin{array}{l}\text { Paired } \\
\text { (t) test } \\
25.861\end{array}$ & $\begin{array}{l}(\mathbf{P}) \\
\text { Value } \\
0.000^{* *}\end{array}$ & $\begin{array}{r}\text { Paired } \\
\text { (t) test } \\
0.645\end{array}$ & $\begin{array}{l}(\mathbf{P}) \\
\text { Value } \\
0.522\end{array}$ & & \\
\hline
\end{tabular}

Independent $t$ test used to determine the Significance between study and control group, paired $t$ test was used to determine the Significance within group, $* \mathrm{P}$ significant at $\leq 0.05$

Table 6. Correlation between the students' total knowledge, HBM and BSE practice scores of the study and control group before and two months after educational intervention $(\mathrm{n}=104)$

\begin{tabular}{cclcccc}
\hline & Variables & \multicolumn{3}{c}{ Total knowledge score } \\
& & & Study group $(\mathbf{n = 5 2})$ & \multicolumn{2}{c}{ Control group (n= 52) } \\
& & & $\boldsymbol{r}$ & $\boldsymbol{P}$ & $\boldsymbol{r}$ & $\boldsymbol{P}$ \\
\hline Total HBM score & - & Before intervention & 0.474 & $0.000 *$ & 0.362 & $0.008 *$ \\
Total practice & - & 2 months after intervention & 0.722 & $0.000 *$ & 0.407 & $0.003 *$ \\
score (BSE) & - & Before intervention & 0.639 & $0.000 *$ & 0.905 & $0.000 *$ \\
\hline
\end{tabular}

r: Pearson correlation coefficient, *P significant at $\leq 0.05$ 
Table 7. Correlation between students' total health beliefs score and their BSE practice score before and two months after educational intervention $(n=104)$

\begin{tabular}{lllllll}
\hline & Variables & \multicolumn{3}{c}{ Total health belief score } \\
& & & \multicolumn{2}{c}{ Study group $(\mathbf{n}=\mathbf{5 2})$} & \multicolumn{2}{c}{ Control group $(\mathbf{n = 5 2})$} \\
& & $\boldsymbol{r}$ & $\boldsymbol{P}$ & $\boldsymbol{r}$ & $\boldsymbol{P}$ \\
\hline BSE practice score & - & Before intervention & 0.626 & $0.000 *$ & 0.434 & $0.001 *$ \\
& - & 2 months after intervention & 0.719 & $0.000 *$ & 0.472 & $0.000 *$ \\
\hline
\end{tabular}

r: Pearson correlation coefficient, $* \mathrm{P}$ significant at $\leq 0.05$

\section{Discussion}

Breast cancer is one of the chief causes of increased mortality and disability among women despite its preventable nature through early detection. This is owing to the widespread lack of knowledge about the nature of the disease, its preventive measures and screening behaviours. Thus, increasing awareness about the disease among the target group is the rational way for saving life and confronting the disease (Mahfouz et al., 2015; Ministry of Health and population, 2015). The current study aimed to evaluate the effect of health belief model-based educational intervention about breast cancer on nursing students' knowledge, health beliefs and BSE practice.

The results of the current study highlighted the significance of health education based on HBM in enhancing nursing students' knowledge about BC as regards its definition, types, risk factors, signs \& symptoms, screening behaviours and treatment methods and BSE. It revealed a significant positive change in mean score of total BC knowledge after educational intervention in the study group than the control group and within the study group before and after educational intervention. Similar improvement were reported by three novel studies; Nahidi et al. (2017). Akhtari-Zavare et al. (2016), Rezaeian et al. (2014) which portrayed that the mean total knowledge score about BC were significantly increased in the experimental than the control group after program implementation. The first evaluate the effect of training using HBM on Iranian women's performance of BSE. The second conducted randomized controlled trial on Malaysian young females to increase breast health awareness. The third assessed the effect of BC educational intervention on Iranian women's knowledge and health beliefs. This highlights the value of the educational intervention on improving knowledge level which is considered the core for health beliefs and attitude development that have a great impact on behaviour change (Ceber et al., 2010; Avci \& Gozum, 2009).

As regard HBM, the present study revealed that the mean score of the total HBM showed significant improvements after educational intervention where students' perceived susceptibility, severity, benefits, cues to action, and self-efficacy about BC were significantly increased whereas their perceived barriers were significantly decreased after educational intervention in the study group than the control group. A significant improvement was also revealed within the study group before and after program implementation.

Concurred findings were presented by two studies; an earlier listed study by Rezaeian et al. (2014) and a Turkish study by Ceber et al. (2010) that was conducted to assess the effectiveness of an educational program on nurses' knowledge, screening behaviours, and health beliefs about BC. Both studies revealed that the mean score of the total HBM was significantly improved after program implementation in the study than the control group. The former, further revealed that all HBM constructs were significantly increased whereas perceived barriers were significantly decreased after program implementation in the intervention than the control group. This idea was also supported by a third study by Musa and Mohamad (2016) which assessed the effect of a health education on prevention of $\mathrm{BC}$ among Malaysian women.

Moreover, three Iranian studies of Masoudiyekta et al. (2018), Farma et al. (2014) and Mood et al. (2011) revealed that HBM based education about $\mathrm{BC}$ was associated with significant improvement in all HBM constructs; perceived susceptibility, severity, benefits, barriers, self-efficacy and cues to action about BC. The first, examined the effect of HBM based education on BC screening behaviours. The second, assessed the effect of HBM based education on BC preventive behaviours among female teachers. The third, evaluated students' BSE practices using the HBM. This highlights the efficiency of HBM based education in modifying students' beliefs about their susceptibility to $\mathrm{BC}$ and its severity as a result of increased their knowledge level about the disease. Moreover, the perceived barriers for engagement in $\mathrm{BC}$ preventive behaviours were decreased with an associated increase in its perceived benefits and students' self-efficacy for performance of such preventive behaviours. 
Notably, the entire evidence share the same results of the present study regarding the effectiveness of health education using HBM in changing persons' health beliefs about BC but several dissimilarities were found regarding the changed constructs of the HBM. First, a recent previously mentioned study of Nahidi et al. (2017) revealed absence of significant difference between study and control groups after program implementation in their perceived benefits, barriers, and severity of BC whereas perceived susceptibility was significantly increased among the study group after educational intervention. This could be attributed to the difference in the sociocultural context and also the women in this contradictory study were preliminary knowledgeable about $\mathrm{BC}$ and its severity and almost have minimal barriers for engaging in $\mathrm{BC}$ preventive practices. This was incongruent with the current study where most of girls prior to the educational intervention reported several barriers for BC screening behaviours as embarrassment, worry and fear of result, cost and its unimportance due to the incurable nature of the disease which were significantly decreased after the educational intervention. Additionally, Abolfotouh et al. (2015) and Eskandari-Torbaghan et al. (2014) showed that perceived barriers were significant predictors of performing BC screening behaviours. The former, examined the effectiveness of HBM in predicting BSE practices among Saudi women. The latter, assesses the effect of using HBM based educational intervention on improving BC Preventive Behaviours among Iranian medical staff.

Moreover, according to HBM susceptibility was found to be significantly linked to individuals' knowledge about the disease (Yilmaz et al., 2017; Farmer et al., 2007). This seems logic as when person are more aware of the disease and that they are at risk, they are more probably engage in disease preventive behaviours. This especially increased when perceived susceptibility is coupled with perceived severity. In addition, the person sensitivity to health issues and consciousness of having asymptomatic disease can prevent unhealthy behaviours and suffering from the disease (Avci \& Gozum, 2009; Yilmaz et al., 2017).

Second, previously mentioned study of Eskandari-Torbaghan et al. (2014) proved that all HBM constructs scores were significantly changed after program implementation in the intervention group than the control group except for perceived seriousness and self-efficacy. The author clarified that by given that the increased persons' perception of disease seriousness can enhance their beliefs in its incurable nature, may result in reverse effects on engaging in preventive behaviours of BC. Thus, they favour to remain don't know if they have the disease rather than to know that they have incurable disease. Such idea is not congruent with the present study and with other two previously mentioned studies of Rezaeian et al. (2014) and Mood et al. (2011) which proved that increased women perception of the disease seriousness can be a motive to take certain preventive behaviours to prevent the disease occurrence. This discrepancy could be explained by the difference in the cultural values and beliefs geared to the health and illness and the difference in sample characteristics in age group ( $\geq 35$ years) and their higher educational level compared to the undergraduate nursing students enrolled in the present study.

Third, a previously mentioned Turkish study by Ceber et al. (2010) proved absence of statistically significant differences between the experimental and control group in perceived susceptibility, severity of BC, benefits and barriers of BSE except for health motivation and self-efficacy and the total score of HBM which were higher in the intervention group. This can be attributed to the difference in the sociocultural context which plays a great role in shaping individuals' frame of reference and attitudes toward health behaviours along with their subjective perception of the social norms placed on these behaviours.

BSE is considered to be the easiest and efficient BC preventive practices. The current study depicted that the mean score of BSE practice significantly increased in the study group than control group after educational intervention and within the study group before and after educational intervention. The effectiveness of HBM based educational intervention in improving BSE practice was congruent with several studies from multiple countries as Iran (Nahidi et al. 2017 and Hajian et al. 2011), Saudi Arabia (Mohamed et al. 2016)' Egypt (Moussa and Shalaby, 2014) and Malaysia (Akhtari-Zavare et al. 2016).

In contrast, a prior listed study by Ceber et al. (2010) revealed absence of significant difference between both groups in BSE practice. This can be attributed to that the majority of the study group in this contradictory study already performs regular monthly BSE which was contrasting to the current study findings where the majority of both groups didn't perform BSE with no significant difference between both groups. In addition to, the higher age range $(25 \geq 45)$ of the studied sample in Ceber et al. (2010) study which force them to focus on performing other screening methods as clinical breast examination and mammography for early detection of BC.

Health beliefs are considered as a major unavoidable part in shaping persons' health behaviours thus it can greatly influence decision to engage in preventive health behaviours The present study revealed that there was a positive statistically significant relationship between nursing students' total health belief score and their observed BSE performance score two months after the educational intervention. These findings were congruent with three 
recent studies; a previously mentioned study by Masoudiyekta et al. (2018), Gonzales et al. (2018)' and Tastan et al. (2011) which found that there was significant relationship between performance of BSE and health beliefs where the perceived barriers, susceptibility and self-efficacy were found to be the most significant predictors of BSE practice. The second, assessed the Saudi women beliefs and behaviour toward BSE practice. The third, assessed BSE associated health beliefs among Turkish nurses.

Conversely, Ceber et al. (2010) found that despite the absence of significant association between health beliefs and BSE, it was frequently performed by the study group more than the control group. The researchers rationalized that by the varied sociocultural context which influences individuals' attitudes towards behaviour performance along with the subjective perceptions of social norms which were relatively ignored by HBM that mainly emphasized the perceived individual beliefs.

Knowledge can play an essential role in shaping individuals' health beliefs and participation in proper health maintenance practices. Thus, it is a basic component for behaviour change along with individuals' beliefs and attitudes (Akhtari-Zavare et al., 2016; Ceber et al., 2010 and Moustafa et al., 2015). The current study portrayed that there was a statistically significant positive correlation between students' total knowledge and health belief scores as well as between knowledge and BSE practice score in both the study and control group after the educational intervention.

Concurred findings were portrayed by several studies. First and second, Yilmaz et al. (2017) and Moustafa et al. (2015) showed that there was a significant positive relationship between BC knowledge and health beliefs as well as between knowledge and BC preventive practices and BSE practice score. The former, studied the effect of training on BC knowledge and beliefs and early detection measures among Turkish women. The latter, conducted an Egyptian study to assess the effectiveness of a BSE educational intervention among university students. Third, Kohler et al. (2017) conducted a study on Malawian women to assess their BC knowledge, behaviours, and preferences. The study explored a significant correlation between knowledge level about $\mathrm{BC}$ and participants' beliefs especially the degree of perceived susceptibility to the disease where most respondents with good $\mathrm{BC}$ knowledge believed that they might get it at any time during their life. This highlights the need to address the misconception about $\mathrm{BC}$ through expanding culturally sensitive educational programs to decrease barriers for BC screening behaviours because these beliefs can impede the persons' motivation to engage in such preventive and early detection measures.

Fourth and fifth, Curtis (2016) and Abolfotouh et al. (2015) utilized the HBM to predict BSE among Saudi women. Both studies proved that the total knowledge level about $\mathrm{BC}$ was significant predictor for performing of $\mathrm{BC}$ screening behaviours. Thus, in accordance with the HBM, this proved that the greater the knowledge about $\mathrm{BC}$ and its preventive behaviours, the greater the awareness about the benefits of these behaviours which further can lower the perceived barriers and increased women's self-efficacy to carry out such preventive behaviours. This further highlights the importance of offering educational intervention at earlier stage of life which can lead to positive and long lasting influence on girls' quality of life through increasing their awareness about BC and its preventive behaviours and/or screening procedures.

Conversely, Kim et al. (2014) conduct a study on Korean immigrant women to assess BC knowledge and perceived health beliefs. They found no significant correlation between women's knowledge and their beliefs about BC screening behaviors, except for perceived barriers which was found to be significant predictor for participating in screening behaviors. The author further correlated that to the higher age range ( $\geq 30$ years) of the studied immigrant women in this contradictory study with less perceived barriers to BC screening behaviours. Moreover, the study proved that country of origin had significant correlation with subjects' knowledge and positive beliefs about BC where they were belonged to four different ethnic groups with multicultural families and varied demographic and cultural background with less health motivation due to preoccupation with resettlement issues.

\section{Conclusion}

Based on the findings of the current study; the study concluded that research hypothesis is supported and the HBM based education is an effective and efficient manner in enhancing girls' BC preventive and screening practices (BSE) and improving their knowledge level and health beliefs about BC. It aids in improving their perceived susceptibility, severity of $\mathrm{BC}$, and perceived benefits with decreased barriers to preventive behaviours with increased their perceived self-efficacy to execute such preventive behaviours.

\section{Recommendations}

Based on results of the current study, the following recommendations can be suggested: 
- Implementation of HBM based educational intervention about BC at different stages of life and settings to reach all targeted women to fight the disease.

- Developing instructional booklets about BC based on HBM to improve their knowledge, health belief, and screening practices.

- Replication of the study on a large probability sample is recommended to achieve more generalization.

\section{Acknowledgements}

The authors would like to express their appreciation and gratitude to all students who willingly participated in the study.

\section{References}

Abolfotouh, M., BaniMustafa, A., Mahfouz, A., Al-Assiri, M., Al-Juhani, A., \& Alaskar, S. (2015). Using the health belief model to predict breast self-examination among Saudi women. BMC Public Health, 15, 1163. https://doi.org/10.1186/s12889-015-2510-y

Akhtari-Zavare, M., Juni, M., Said, S., Ismail, I., Latiff, L., \& Eshkoor, S. (2016). Result of randomized control trial to increase breast health awareness among young females in Malaysia. BMC Public Health, 16, 738. https://doi.org/10.1186/s12889-016-3414-1

American College of Obstetricians and Gynaecologists. (2011). Practice bulletin no. 122: Breast cancer screening. Obstet Gynecol, $118(2 \mathrm{Pt}$ 1), 372-382.

Anothaisintawee, T.H., Wiratkapun, C.H., Lerdsitthichai, P., Kasamesup, P., Wongwaisayawan, S., Srinakarin, J., ... Thakkinstian, A. (2013, September). Risk Factors of Breast Cancer: A Systematic Review and Meta-Analysis. Asia-Pacific Journal of Public Health, 25(5), 1-20. https://doi.org/10.1177/1010539513488795

Arevian, M., Noureddine, S., \& Abboud, S. (2011). Beliefs related to breast cancer and breast cancer screening among Lebanese Armenian Women. Health Care Women Int., 32(11), 972-989. https://doi.org/10.1080/07399332.2011.580405

Avci, I.A., \& Gozum, S. (2009). Comparison of two different educational methods on teachers' knowledge, beliefs and behaviors regarding BC screening. Eur $J$ Oncol Nurs, 13, 94-101. https://doi.org/10.1016/j.ejon.2009.01.004

Bacon, J.L., \& Tomich, P.G. (2017). Obstetrics and Gynecology: Maintenance of Knowledge: An Issue of Obstetrics and Gynecology Clinics (1st ed.). Elsevier Health science, South Carolina.

Ceber, E., Turk, M., \& Ciceklioglu, M. (2010). The effects of an educational program on knowledge of BC, early detection practices and health beliefs of nurses and midwives. Journal of Clinical Nursing, 19(15-16), 2363-2371. https://doi.org/10.1111/j.1365-2702.2009.03150.x

Champion, V.L. (1993). Instrument refinement for breast cancer screening behaviors. J Nurs Res, 42(3), 139-143. https://doi.org/10.1097/00006199-199305000-00003

Chanay, M.D., \& Anderson, B.A. (2016). Caring for the Vulnerable, perspectives in nursing theory, practice and research (4th ed.). Jones \& Bartlett Publishers, 153.

Curtis, A. (2016). Health Belief Model and Fatalism related to Breast Cancer Screening in Working Women. Published dissertation, Faculty of Auburn University. Retrieved March 26, 2008, from https://etd.auburn.edu/handle/10415/5262

Eskandari-Torbaghan, A., Kalan-Farmanfarma, K., Ansari-Moghaddam, A., \& Zarei, Z. (2014). Improving BC Preventive Behavior among Female Medical Staff: The Use of Educational Intervention based on Health Belief Model. The Malaysian Journal of Medical Sciences, 21(5), 44-50.

Farma, K., Jalili, Z., Zareban, I., \& Pour, M. (2014). Effect of education on preventive behaviors of breast cancer in female teachers of guidance schools of Zahedan city based on health belief model. J Educ Health Promot., 3, 77.

Farmer, D., Reddick, B., D’Agostino, R., \& Jackson, S.A. (2007). Psychosocial correlates of mammography screening in older African American women. Oncol Nurs Forum, 34, 117-123. https://doi.org/10.1188/07.ONF.117-123 
Ghanbary, M.K., Shamsi, M., Khorsandi, M., Farazi, A., Ranjbaran, M., \& Eshrati, B. (2015). Effect of training with teaching methods designed based on health belief model on knowledge and self-efficacy in nurses on the disciplines standard precautions in hospitals. Journal of human health, 1(2), 51-55.

Gonzales, A., Alzaatreh, M., Mari, M., \& Alloubani, A. (2018). Beliefs and behavior of Saudi women in the University of Tabuk toward breast self-examination Practice. APJCP., (19), 121-126.

Hajian, S., Vakilian, K., Najabadi, K.H., Hosseini, J., \& Mirzaei, H. (2011). Effects of Education Based on the Health Belief Model on Screening Behavior in High Risk Women for BC, Tehran, Iran. Asian Pacific Journal of Cancer Prevention, 12, 49-54. https://doi.org/10.1016/S0959-8049(12)70190-9

Harris, J.R., Lippman, M.E, Morrow, M., \& Kent Osborne, C. (2014). Diseases of the breast: Physical Exam of the Breast (5th ed.). Philadelphia: Wolters Kluwer Health Adis (ESP).

Ibrahim, A., Khaled, H., Mikhail, N., Baraka, H., \& Kamel, H. (2014). Cancer Incidence in Egypt: Results of the National Population-Based Cancer Registry Program. Hindawi Publishing Corporation. Journal of Cancer Epidemiology, 1-18. https://doi.org/10.1155/2014/437971

Ignatavicius, D.D., \& Workman, M.L. (2016). Medical-Surgical Nursing: Patient-Centered Collaborative care (8th ed.). Elsevier Health science, Canada.

Jemal, A., Siegel, R., Xu, J., \& Ward, E. (2010). Cancer statistics. CA Cancer J Clin, 60(5), 277-300. https://doi.org/10.3322/caac.20073

Kim, J., Lee, S.K., Lee, J., Choi, M.Y., Jung, S.P., Kim, M., ... Kil, W.H. (2014). BC Screening Knowledge and Perceived Health Beliefs among Immigrant Women in Korea. Journal of BC, 17(3), 279-86.

Kim, J., Menon, U., Wang, E., \& Szalacha, L. (2010). Assess the effects of culturally relevant intervention on breast cancer knowledge, beliefs, and mammography use among Korean American Women. J Immigr Minor Health, 12, 586-597. https://doi.org/10.1007/s10903-009-9246-7

Kohler, R., Gopal, S., Lee, C., Weiner, B., Reeve, B., \& Wheeler, S. (2017). BC Knowledge, Behaviors, and Preferences in Malawi: Implications for Early Detection Interventions from a Discrete Choice Experiment. Journal of Global Oncology, 21, 1-10. https://doi.org/10.1200/JGO.2016.005371

Lin, Z.C., \& Effken, J.A. (2010). Effects of a tailored web-based educational intervention on women's perceptions of and intentions to obtain mammography. $J$ Clin Nurs., 19, 1261-1269. https://doi.org/10.1111/j.1365-2702.2009.03180.x

Mahfouz, A.A., Hassanein, M.H., Nahar, S., Farheen, A., Gaballah, II., Mohamed, A., ... Aftab, R. (2013). Breast cancer knowledge and related behaviors among women in Abha city, Southwestern Saudi Arabia. $J$ Cancer Educ., 28(3), 516-520. https://doi.org/10.1007/s13187-013-0495-8

Masoudiyekta, L., Rezaei-Bayatiyani, H., Dashtbozorgi, B., Gheibizadeh, M., Malehi, A.S., \& Moradi, M. (2018). Effect of education based on health belief model on the behavior of breast cancer screening in women. Asia Pac J Oncol Nurs, 5,114-120.

Michael, B. (2017). Breast Cancer Update. Windsong Radiology Group. Retrieved March 26, 2018, from http://blog.chsbuffalo.org/wp-content/uploads/2016/12/01-17-2017-Dr.-Peyser-Breast-Cancer-Update.pdf

Ministry of Health and Population/Egypt, El-Zanaty and Associates/Egypt, and ICF International. (2015). Egypt Health Issues Survey. Cairo, Egypt: Ministry of Health and Population/Egypt and ICF International. Retrieved March 26, 2018, from https://dhsprogram.com/pubs/pdf/FR313/FR313.pdf

Mohamed, H., Ibrahim, Y., Lamadah, S., \& Abo El-Magd, M. (2016). Application of the Health Belief Model for BC Screening and Implementation of Breast Self- Examination Educational Program for Female Students of Selected Medical and Non-Medical Faculties at Umm al Qura University. Life Science Journal 13(5), 21-33.

Mood, M., Sharifirad, G.R., Hossein, S., \& Sharifzadehe, G. (2011). Evaluation of breast self-examination program using Health Belief Model in female students. Journal of Research in Medical Sciences: The Official Journal of Isfahan University of Medical Sciences, 16(3), 316-322.

Moussa, M., \& Shalaby, N. (2014). Effect of Breast Self-Examination Education Program on Knowledge, Attitude and Practice of Nursing Students. International Journal of Research Studies in Biosciences, 2(6), $40-49$. 
Moustafa, D., Abd-Allah, E., \& Taha, N. (2015). Effect of a Breast-Self Examination (BSE) Educational Intervention among Female University Students. American Journal of Nursing Science, 4(4), 159-165. https://doi.org/10.11648/j.ajns.20150404.13

Musa, S., \& Mohamad, N. (2016). Effectiveness of a health education intervention for breast cancer prevention among women. E-Journal of Research and Innovation, III(I),103-122.

Nahidi, F., Dolatian, M., Roozbeh, N., Asadi, Z., \& Shakeri, N. (2017). Effect of health-belief-model-based training on performance of women in breast self-examination. Electronic Physician, 9(6), 4577-4583. https://doi.org/10.19082/4577

Obaji, N.C., Elom, H.A., Agwu, U.M., Nwigwe, C.G., Ezeonu, P.O., \& Umeora, O.U. (2013). Awareness and Practice of Breast Self-Examination among Maket Women in Abakaiki, South East Nigeria. Annals of Medical and Health Sciences Research, 3(1), 7-12. https://doi.org/10.4103/2141-9248.109457

Oeffinger, K.C., Fontham, E.T., Etzioni, R., Herzig, A., Michaelson, J.S., Shih, Y.C., ... Wender, R. (2015). American Cancer Society. Breast cancer screening for women at average risk: 2015 guideline update from the American Cancer Society. JAMA, 314(15), 1599-1614. https://doi.org/10.1001/jama.2015.12783

Othman, A., Ahram, M., Al-Tarawneh, M.R., \& Shahrouri, M. (2015). Knowledge, Attitudes and Practices of Breast Cancer Screening Among Women in Jordan. Health Care Women Int., 36(5), 578-592. https://doi.org/10.1080/07399332.2014.926900

Oyekale, A.S., \& Oyekale, T.O. (2010). Application of health belief model for promoting behaviour change among Nigerian single youth. Afr J Reprod Health, 14(2), 63-75.

Rezaeian, M., Sharifirad, G., Mostafavi, F., Moodi, M., \& Abbasi, M.H. (2014). The effects of BC educational intervention on knowledge and health beliefs of women 40 years and older, Isfahan, Iran. Journal of Education and Health Promotion, 3(43), 59-64.

Russell, K.M., Champion, V.L., Monahan, P.O., Millon-Underwood, S., Zhao, Q., Spacey, N. et al. (2010). Randomized trial of a lay health advisor and computer intervention to increase mammography screening in African American women. Cancer Epidemiol Biomarkers Prev., 19, 201-210. https://doi.org/10.1158/1055-9965.EPI-09-0569

Shalini, Varghese, D., \& Nayak, M. (2011). Awareness and impact of education on breast self- examination among college going girls. Indian J Palliat Care, 17(2), 150-154. https://doi.org/10.4103/0973-1075.84538

Singh, M., \& Jangra, B. (2013). Association between body mass index and risk of breast cancer among females of north India. South Asian Journal of Cancer, 2(3), 121-125. https://doi.org/10.4103/2278-330X.114108

Tastan, S., Iyigün, E., \& Unver, V. (2011). Health Beliefs Concerning Breast Self-examination of Nurses in Turkey. Asian Nursing Research, (5), 151-156. https://doi.org/10.1016/j.anr.2011.09.001

United Nations, 'World Cancer Day: 4 February 2017'. (2017). Retrieved March 25, 2018, from http:www.un.org/en/events/cancerday

World Health Organization (WHO). (2018). World Cancer Day. Retrieved March 25, 2018, from http://www.who.int/cancer/world-cancer-day/2018/en/

World Health Organization. (2012). Health education: theoretical concepts, effective strategies and core competencies, WHO Regional Office for the Eastern Mediterranean, Cairo. Retrieved March 26, 2018, from http://applications.emro.who.int/dsaf/EMRPUB_2012_EN_1362.pdf

Yarbro, C.H., Frogge, M.H., \& Goodman, M. (2011). Cancer nursing (6th ed.). Jones and Bartlett publishers, Inc. London, 1120.

Yilmaz, M., Sayın, Y., \& Oner Cengiz, H. (2017). The Effects of Training on Knowledge and Beliefs about BC and Early Diagnosis Methods among of Women. Eur J Breast Health, 13, 175-182. https://doi.org/10.5152/tjbh.2017.3255

\section{Copyrights}

Copyright for this article is retained by the author(s), with first publication rights granted to the journal.

This is an open-access article distributed under the terms and conditions of the Creative Commons Attribution license (http://creativecommons.org/licenses/by/4.0/). 